\title{
Editorial
}

\section{Errores médicos}

(Medical Errors)

En todas las actuaciones de los seres humanos, los errores son una realidad innegable. Por ser el ejercicio de la medicina algo que afecta directamente a las personas, este tema es uno de los más controvertidos, tanto en el nivel profesional como en los medios de comunicación, que siempre están ávidos de noticias impactantes y las destacan con titulares como los siguientes:

"Sobre irradiación de109 pacientes con cobalto en el hospital San Juan de Dios". La Nación 11-10-1997.

"Un menor de 14 años entró en coma durante la intervención por una fractura de la muñeca y murió a causa de un paro cardiorrespiratorio". La Nación 24 -5-1997

"Indagan denuncia por malpraxis Niño con parálisis cerebral" La Nación 10-1-1998

Es un problema difícil de definir porque se trata de las actuaciones del personal de los sistemas de salud, que producen lesiones de distinta gravedad, algunas de las cuales pueden simplemente aumentar los periodos de internamiento o de tratamiento del paciente mientras, mientras otras pueden dejar secuelas permanentes y, en su grado máximo, hasta ocasionar la muerte.

Suceden en todo el mundo, y son la séptima causa de muerte. En ciertos lugares, donde el fenómeno ha sido estudiado con detalle, se han reportado cifras alarmantes es el caso de los Estados Unidos, (Cuadro 1).

\begin{tabular}{|c|c|c|}
\hline \multicolumn{3}{|c|}{$\begin{array}{l}\text { Cuadro 1. Errores médicos como causa de muerte en los hospitales } \\
\text { de los Estados Unidos }\end{array}$} \\
\hline Origen de los datos & $\begin{array}{l}\text { Año cuando se realiza el } \\
\text { estudio }\end{array}$ & Número de muertos/ año \\
\hline Colorado y Utáh ${ }^{1}$ & 1997 & 44,000 \\
\hline Instituto de Medicina ${ }^{2}$ & 1998 & 96,000 \\
\hline $\begin{array}{l}\text { Andersen y Smith } \\
\text { Nacional Vital Stadistic report }\end{array}$ & 2002 & 200,000 \\
\hline
\end{tabular}

ISSN 0001-6002/2009/51/1/7-9 Acta Médica Costarricense, (C2009 Colegio de Médicos y Cirujanos 
Es necesario cambiar la cultura que hemos tenido por muchos años de señalar el error y buscar un culpable; nuestro objetivo debe ser analizar la ruta que nos llevó a que esto sucediera. Es preciso plantearnos tres preguntas básicas: ¿Qué pasó?, ¿Por qué pasó? ¿Qué tenemos que hacer para que esto no vuelva a suceder? Desafortunadamente, los datos que tenemos no nos indican que se esté haciendo mucho en ese sentido, ni en el país ni en otros sitios. Existen esfuerzos, como el estudio de los efectos adversos dentro de los hospitales, programa impulsado por la OPS, que de continuarse como ha empezado, nos ofrecerá resultados en el corto plazo. ¡Esperemos que tenga continuidad y no pierda su norte!

Al estudiar los errores cometidos se ha podido comprobar que la mayoría de los que producen lesiones serias han sucecido encadenados. Esto lo presenta muy claramente James Reason, en un dibujo que no reproducimos por carecer de autorización. En él se muestran 4 rebanadas de queso suizo con sus agujeros y una flecha roja que atraviesa los que se encuentran alineados. Así se demuestra dos cosas: que los errores están encadenados y que al eliminar una de las rebanas - un médico o enfermera - no se evitarán, porque lo que hay que hacer es modificar el sistema para que los orificios no estén alineados y se rompa la cadena.

Conscientes de la importancia que tiene un sistema que mejore la seguridad de los pacientes, debemos preguntarnos: ¿Cuáles son las medidas por tomar para lograr tal objetivo?

Es necesario formar en todas las instituciones un grupo interdiciplinario que incluya expertos, representantes del personal directamente en contacto con el paciente y representantes de los pacientes. Este grupo buscará las causas y su palabra más usada debe ser por qué, por qué y por qué... es la única manera de encontrar dónde están las acciones que ocasionaron el error. Todo esto debe hacerse teniendo como principio fundamental la prevención de futuros errores y no la búsqueda de un culpable. Se deben analizar acciones humanas, el material necesario para realizarlas y todo el proceso.

Aceptar y aplicar una política enfocada a la prevención no significa que todo será aceptado, ya que los errores que se deban a impericia, descuido, dolo, o abuso, --tanto de alcohol por parte de profesionales o contra la moral de los pacientes, deben ser de conocimiento público y remitidos a la justicia.

Las anteriores son las recomendaciones de los hospitales de veteranos de los Estados Unidos, que se han convertido en unos de los mejores centros hospitalarios de ese país. Ellos tomaron las ideas de las empresas que también tienen que afrontar grandes riesgos, tales como las de aviación y todas las relacionadas con la energía atómica.
La existencia de un sistema que recoja la información de estos errores es esencial. La simple recolección de datos sin que estos se usen para tomar medidas correctivas es no solo una función inútil, sino que perjudicial, pues el tiempo que las personas utilizan en introducir los datos al sistema podría emplearse más adecuadamente en otras funciones.

Dado que los errores que producen lesiones serias o la muerte se presentan en el $79 \%$ de los casos en la prescripción de los medicamentos, los analizaré en detalle. Lo primero que debemos comprender es que cuando se prescribe un medicamento a un paciente hospitalizado este acto representa entre 80 y 200 pasos, en cada uno de los cuales pueden producirse errores. Para su mejor comprensión solo mencionaremos los 5 más importantes: la prescripción del medicamento, la transcripción de ese acto a la farmacia, la preparación de este, el transporte de donde se ha preparado a donde se va a administrar y, finalmente, su administración. Cada uno de ellos a su vez implica otros tantos pasos. Como es lógico suponer, es en el proceso de administración realizado por las enfermeras y en el de preparación y distribución a cargo de las farmacias, donde se encontraron la mayoría de los errores. Los errores pueden ser desde un simple olvido de la hora de administración, hasta la sustitución de un medicamento por otro. Debe existir una clasificación, que use el lenguaje correcto, para que los datos de los sistemas sean fiables.

En los pacientes de las unidades de cuidados intensivos es en quienes existen mayores posibilidades de cometer errores, ya que su población requiere un mayor número de medicamentos, algunos de muy cuidadosa administración, así como una mayor cantidad de intervenciones invasivas.

La comisión encargada de evitar los errores debe estandarizar los medicamentos y su forma de usarlos; los médicos deben realizar las órdenes en un sistema computarizado que las envíe a la farmacia, donde por medio del código de barras tomado del paciente, se pueda controlar si existen, alergias, efectos adversos al medicamento, incompatibilidades y asegurar, que la dosis prescrita sea la correcta. Todo lo anterior se efectúa mediante una computadora, cuyo programa, cuando exista una violación de estos estándares, emitirá una alerta. Además de estas medidas, la enfermera, al administrar los medicamentos deberá comprobar que los códigos de barras de estos y del paciente concuerden.

El avance acelerado de la medicina obliga a todas las instituciones que brindan servicios a mantenerse acreditadas con determinados estándares. Esto que se le está empezando a pedir a nuestras universidades debe hacerse también con los sistemas de salud, pues es otra forma de garantizar la seguridad de los servicios brindados. 
El aumento en los procedimientos utilizados expone a mayores posibilidades de error, pero este avance tecnológico no nos debe apartar de lo más valioso que siempre hemos tenido: escuchar al paciente, oír con atención y calma lo que él, que es el enfermo, está sintiendo. Sigue siendo este el mejor método diagnóstico y cuando se desprecia y se cambia por la tecnología, los errores se presentan con mayor frecuencia. No se puede, ante este postulado, dejar de preguntarse: ¿cómo es posible en nuestro sistema de salud, oír pacientemente el relato de un padecimiento que puede tener años de evolución, condensado en los únicos 15 minutos, fijados para atender a cada uno de los enfermos? ¿Será esta la causa de que se estén enviando tantos procedimientos caros e innecesarios, y también de que se comentan algunos errores?
De lo anterior podríamos concluir que los errores médicos deben evitarse para garantizar la seguridad de los pacientes. Sin embargo, no es solo la mayor vigilancia sobre las acciones del personal de salud lo que va a evitarlos, sino que es imprescindible un abordaje que identifique sus causas y rediseñe un sistema que las evite, para lograr lo único que es fundamental: que no se cometan.

Carlos Arrea-Baixench

Miembro de Número

Academia Nacional de Medicina 